\title{
Design and Implementation of a Structural Health Monitoring System for a Large Sea-Crossing Project with Bridges and Tunnel
}

\author{
Yu Yan, ${ }^{1,2}$ Xingquan Mao, ${ }^{3}$ Xu Wang $\mathbb{D}^{1},{ }^{1}$ Xianfeng Yu $\mathbb{D},{ }^{4}$ and Lei Fang ${ }^{2}$ \\ ${ }^{1}$ School of Civil Engineering, Chongqing Jiaotong University, Chongqing 400074, China \\ ${ }^{2}$ Hong Kong-Zhuhai-Macao Bridge Authority, Zhuhai 519060, Guangdong, China \\ ${ }^{3}$ CCCC Highway Consultants Co., Ltd., Beijing 100088, China \\ ${ }^{4}$ School of Civil Engineering \& Transportation, South China University of Technology, Guangzhou 510640, Guangdong, China \\ Correspondence should be addressed to Xianfeng Yu; ctxfyu@scut.edu.cn
}

Received 19 July 2019; Revised 25 September 2019; Accepted 5 November 2019; Published 22 November 2019

Guest Editor: Franco Concli

Copyright ( $2019 \mathrm{Yu}$ Yan et al. This is an open access article distributed under the Creative Commons Attribution License, which permits unrestricted use, distribution, and reproduction in any medium, provided the original work is properly cited.

\begin{abstract}
Even though large-scale projects, such as sea-crossing bridges and tunnels, have complex structures and service conditions, the structural health monitoring (SHM) system can comprehensively monitor the stress situation and damage evolution law in the entire construction and service process of such structures. Based on the background of the Hong Kong-Zhuhai-Macao Bridge, this study systematically introduces the overall goal and framework of the SHM system, monitoring content, and sensor information. Moreover, the structural health condition evaluation methods and data analysis methods are presented in detail. Then, on the basis of a multilayer data storage system, a fault-tolerant data center platform design, an open integrated supervision platform design, and other measures, a set of reliable and advanced large-scale software systems are built to achieve the SHM system for the Hong Kong-Zhuhai-Macao Bridge. Finally, the wind characteristics around the Hong Kong-Zhuhai-Macao Bridge and some of the monitored structural responses from the Super Typhoon Mangkhut in 2018 are shown, which verified that the SHM system can accurately and reliably monitor and feedback the environmental load and structural response of the principal parts of the Hong Kong-Zhuhai-Macao Bridge under complicated service environment.
\end{abstract}

\section{Introduction}

Societal and economic development has led to the continuous construction of large-span bridges and underground tunnels over rivers, lakes, and seas. These projects are large in scale and structurally complex and have harsh service environment. Compared with underground tunnels, a bridge structure is more lightweight and flexible. However, it easily suffers from frequent traffic loads, fluctuating wind loads, rainstorm attacks, and temperature effects. Structural performance can easily degrade under the above loads or actions, posing a risk to the safe operation of the structure and even causing collapsed accidents [1-4]. Monitoring these large-span bridges and tunnels in real time, finding the damage degree of the structures in time, predicting the performance changes of the structure, and taking effective means to diagnose the structures have become the key problems that must be solved urgently in modern large-scale projects. A structural health monitoring (SHM) system can comprehensively monitor the stress situation and damage evolution law of bridge and tunnel structures during the entire process of construction and service. Moreover, it can effectively ensure the construction and service safety of large-span structures [5].

At present, researchers have conducted studies on corresponding SHM systems in terms of various forms of building structures [6] and bridge structures $[7,8]$. Moreover, some new sensors and methods have been invented to assist the response monitoring of building and bridge structures [9-13]. To evaluate the health condition of shear connections, Li et al. [14] proposed a relative displacement sensor to measure directly the relative slip between slab and girder in composite bridges, and the accuracy of the developed sensor was tested on a composite bridge model in 
the laboratory. Experimental results showed that the developed sensor was highly sensitive to relative displacement and performed well for the SHM of composite bridges. Zhou et al. [15] comprehensively introduced the design and realization of an intelligent health monitoring system for the Jiubao Bridge in China. The SHM system was integrated with several novels and practice-based concepts, such as life cycle concerns for system design and implementation, newly designed high-performance sensors, modularized hardware and software, multilevel data management, multiscale condition evaluation, and reliable warning strategies. On this basis, Chen et al. [5] reviewed the application of health monitoring technology in large-span bridges in recent years and summarized the data analysis techniques, such as structural modal identification and signal processing. Meanwhile, considering the Jiubao Bridge, which is a typical large-span arch bridge, they introduced the various parts of the bridge health monitoring system in detail. For a cablestayed bridge, Wang et al. [16] introduced a long-term monitoring system for the wind characteristics of the Sutong Bridge. Based on the SHM monitoring data of the Donghai Bridge, the wind characteristics (turbulence intensity, turbulent integral scale, and power spectral density) around the Sutong Bridge were analyzed using the collected time course data of wind speed and direction during the crossing of Typhoon Kalmaegi and Typhoon Fung-Wong. Zhou and Sun [17] studied the vibration response and modal parameter variation of the Donghai Bridge during high winds. Results showed the following: (1) The root mean square (RMS) of the wind-induced acceleration increased with the mean wind speed in an approximately quadratic curve relation. (2) The modal parameter estimation suffered a relatively large uncertainty. For cable-stayed bridges, a wind and SHM system for the Tsing Ma suspension Bridge in Hong Kong was introduced by $\mathrm{Xu}$ et al. [18], and the measurement data were analyzed to obtain the mean wind speed, mean wind direction, mean wind inclination, turbulence intensity, integral scale, gust factor, wind spectrum, acceleration response, and natural frequency of the bridge after Typhoon Victor in 1997. Wang et al. [19] obtained and analyzed the wind measurement data during strong winds from the wind environment monitoring subsystem of the Runyang Suspension Bridge. Koo et al. [20] presented experience and lessons from the SHM practice in the Tamar Bridge in Plymouth, UK, a $335 \mathrm{~m}$ span suspension bridge.

Research on various forms of bridge health monitoring systems has been perfected, but that on the health monitoring systems of tunnel engineering is relatively few. During underground tunnel operations, structural performance can inevitably degrade due to the combined effects of the stochastic and disadvantageous environments [21]. Yang et al. [22] introduced a real-time automatic monitoring system, which was installed in an underwater tunnel to evaluate its performance under normal operating conditions.

As mentioned above, the SHM systems have been established for various types of large-span bridges, and their application in tunnel engineering has been preliminarily studied. However, for ultralarge sea-crossing projects with a line length of over $50 \mathrm{~km}$ (including multiple sea-crossing bridges and immersed tunnels), no corresponding case of health monitoring system design and realization was found. The design and realization of a SHM system has been introduced based on the main project of the Hong KongZhuhai-Macao Bridge, and a preliminary analysis of its monitoring data, which were obtained when Typhoon Mangkhut hit the construction area in 2018, has been conducted. Results verify the effectiveness of the health monitoring system of the bridge.

\section{Overview of the Hong Kong-Zhuhai-Macao Bridge}

The Hong Kong-Zhuhai-Macao Bridge, a large-scale seacrossing corridor connecting Hong Kong, Zhuhai, and Macao, is an integral part of the Pearl River Delta Regional Loop in the planning of the National Highway Network and a key project that spans the Lingding Channel. It is a $55 \mathrm{~km}$ bridge-tunnel system consisting of three cable-stayed bridges over the main navigable channel (Jiuzhou, Jianghai, and Qingzhou Shipping Channel Bridges), an undersea tunnel and four artificial islands. It also consists of viaducts and tunnels, which connect the main structures and link roads in the three cities.

The Jiuzhou Shipping Channel Bridge is a single-cable plane, steel-concrete composite box girder, and twin-pylon cable-stayed bridge. Its main navigational opening is the center span of the bridge, which allows two-way navigation. The length of the five spans of the bridge is arranged as 85 , $127.5,268,127.5$, and $85 \mathrm{~m}$, and the full length of the bridge is $693 \mathrm{~m}$. The section of the main beam is a high-performance concrete bridge decking combined with a separated open steel box girder. The cable-bent towers are steelconcrete composite structures featuring a sail shape, as shown in Figure 1.

The Jianghai Shipping Channel Bridge is a large steel box girder cantilever cable-stayed bridge with three cable-bent towers, a single support column, and a single cable plane. The lengths of its four spans are 129, 258, 258, and $129 \mathrm{~m}$. A $110 \mathrm{~m}$ length side span is set at two sides of the bridge, and the steel cable-bent towers feature a dolphin shape, as shown in Figure 2.

The Qingzhou Shipping Channel Bridge is a large steel box girder cantilever cable-stayed bridge with two cable-bent towers and two cable planes. The five spans of the bridge are $110,236,458,236$, and $110 \mathrm{~m}$ long, totaling $1150 \mathrm{~m}$. The main girder adopts a large cantilever integral steel boxed girder, and the remaining cables adopt sector arrangement and two cable planes. The cable tower adopts a transverse $\mathrm{H}$-shaped frame, and its upper beam features a Chinese knot shape, as shown in Figure 3.

The tunnel section is $6265 \mathrm{~m}$ long across the Lingding West and Tonggu Channels. The immersed tunnel length is $5664 \mathrm{~m}$, which is the longest in the world. A section of the tunnel element has two bores and one middle gallery. The immersed tunnel provides a dual three-lane carriageway with a width of $2 \times 14.25 \mathrm{~m}$ and a vertical clearance of $5.1 \mathrm{~m}$, as shown in Figure 4. 


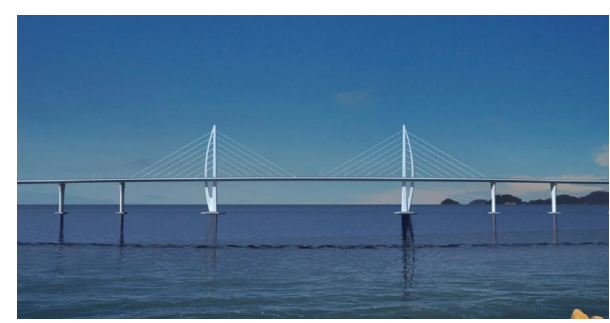

FIgURE 1: Jiuzhou Shipping Channel Bridge.

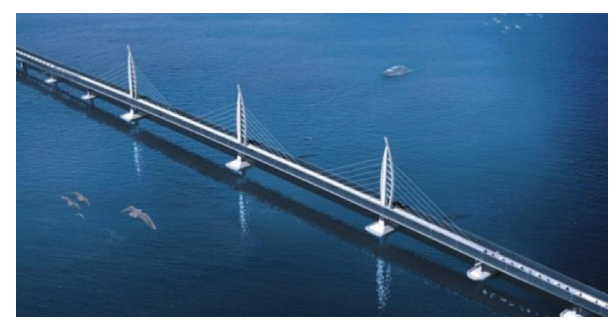

Figure 2: Jianghai Shipping Channel Bridge.

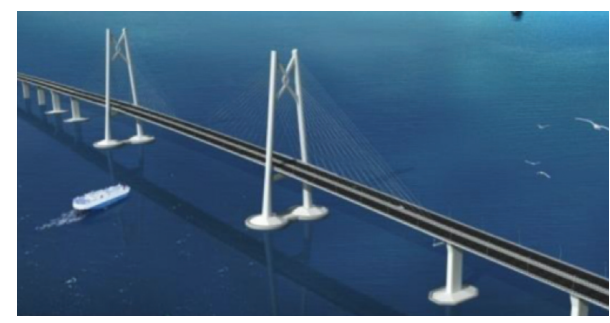

Figure 3: Qingzhou Shipping Channel Bridge.

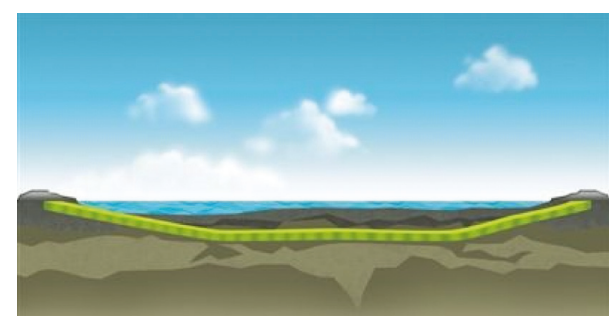

Figure 4: Immersed tunnel.

\section{Design of the Bridge Health Monitoring System}

3.1. Overall Objective and Framework of the Monitoring System. The Hong Kong-Zhuhai-Macao Bridge is located in a typhoon-prone region. The structure in the long-term service process with environmental erosion, material aging, long-term load effects, fatigue effects, sudden disasters, and other factors will inevitably lead to structural and system damage accumulation and resistance attenuation. The operational safety of the Hong KongZhuhai-Macao Bridge is ensured, and the occurrence of catastrophic accidents is avoided by the SHM and inspection management systems. The systems, combining automated health monitoring technology with manual inspection technology, are technologically advanced, reasonable, economic, easy to manage, open, compatible, and in line with the requirements of the Hong KongZhuhai-Macao Bridge. Contemporary equipment and technologies, such as modern sensor testing, signal analysis, remote intelligent control, computer technology, damage identification, and structural safety assessment, are adopted in the design and realization of the systems.

An SHM and security warning system is established through three-layer $\mathrm{C} / \mathrm{S}$ and $\mathrm{B} / \mathrm{S}$ hybrid structures based on the GIS platform and distributed database management system combined with Internet technology. The communication optical cable transmission network works as an information transmission platform. The structural on-site monitoring station and remote monitoring center are linked to be an organic whole. Remote users can connect to the on-site monitoring station through the Internet. Meanwhile, the system can be controlled and configured through the network, and the structural health state assessed by the system can also be obtained. The overall framework of the system is shown in Figure 5.

The system is divided into an on-site monitoring station and monitoring center in physical locations. The on-site monitoring station mainly places data acquisition equipment, including a demodulation instrument, a vibration collector, and digital signal acquisition equipment, in which the inspection terminal device is provided to the inspectors who work for the developers. The inspectors can input the inspection dynamic data and manage these data using the inspection terminal equipment. The monitoring center places the various servers required by the system, including data acquisition, data analysis, and web and database servers. After system deployment is completed, the user uses the system through a software interface. The physical deployment diagram of the system is shown in Figure 6.

3.2. Monitoring Content and Sensor Information. The Hong Kong-Zhuhai-Macao Bridge SHM work includes the Jiuzhou, Jianghai, and Qingzhou Shipping Channel Bridges and a nonnavigable bridge with a representative structure form. The permanent monitoring contents are as follows: (1) critical environmental loading (including wind velocity and direction, external and internal temperatures, humidity, transportation loading, and earthquake loading); (2) deformation of critical structure member and control cross section (main beam and tower crane); (3) strain and temperature of critical control cross section; (4) stress monitoring on cable structure; (5) dynamic and vibration characteristic monitoring (inherent dynamic characteristic and vibration response); (6) monitoring of support reaction (support reaction of bridge tower, auxiliary pier, and transition pier); and (7) monitoring of erosion process (concrete erosion). The monitoring contents and corresponding sensors are presented in Table 1.

For example, 277 sensors were installed on the section of the Qingzhou Shipping Channel Bridge with the largest 


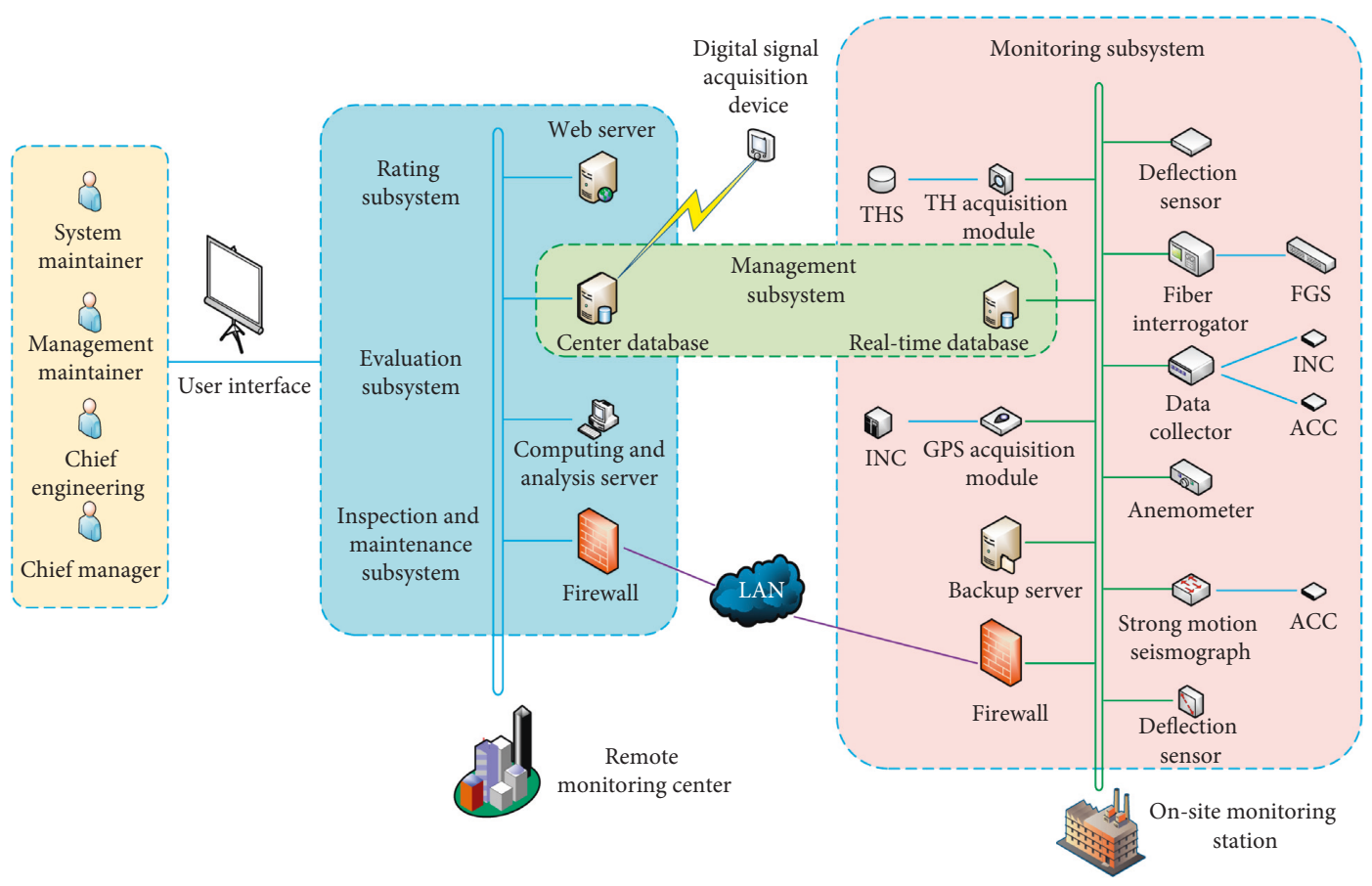

FIgURE 5: Overall framework of the monitoring system.

span, and the general layout of the measurement points is shown in Figure 7.

3.3. Structural Health Condition Evaluation and Data Analysis Methods. Comprehensive evaluation of the structural health state and postdata processing methods are very important to a SHM system, so the following sections describe evaluation methods and data analysis methods.

\subsubsection{Evaluation Methods on Structural Health Condition.}

The application of structural evaluation technology, evaluation computational model, and evaluation expert system, which are developed on the basis of fuzzy mathematics and random theory, has expanded the range of the structural health evaluation theory. In addition, the target of evaluation has changed from one or several specific structural members to the entire bridge. At present, the widely applied methods of structural health evaluation are the reliability theory, analytic hierarchy process (AHP), fuzzy theory, and genetic algorithm.

(1) Analytic Hierarchy Process. Analytic hierarchy process (AHP) [23] was first proposed by Satty in the 1970s. This quantitative method is used for multi-index comprehensive evaluation. The initial weight of each evaluation index is defined to quantify the qualitative factor, thereby minimizing the effect of subjective factors and making the evaluation scientific.

(2) Fuzzy Theory Evaluation. Some qualitative factors are transformed into quantitative factors by adopting the principle of fuzzy relation composite to achieve fuzziness.
The certainty of the algorithm coordinates with each other, making the process objective. However, problems on selecting a fuzzy calculation model and membership function, avoiding uncertainty and randomness during the entire matrix formation, have not been appropriately solved.

(3) Method Based on the Reliability Theory. In the evaluation method based on the reliability theory, the failure probability and reliability indices are used to assess structural safety. In this method, the uncertainty of loading or resistance and the effect of irregular change on the structure can be solved due to the probability theory. The probability theory is still in the primary stage to be applied in the evaluation of structural health and mainly in the capacity assessment of the structural elements. However, this method still requires improvement when assessing the entire structure.

(4) Genetic Algorithm and Neural Network Method. The genetic algorithm [24], which is based on genetics and natural selection, has tremendous benefits in automatic optimization, whereas neural networks [25] have a great pattern recognition ability. Thus, both approaches are suitable in the application of structural evaluation. However, this method is still in the stage of theoretical research and model deduction and rarely in practical application.

3.3.2. Data Analysis Methods. After obtaining the time histories of various monitoring variables such as wind speed and structural displacement, some statistic results (mean value and standard deviation) can be easily done. Besides, many mathematic methods, as shown in Table 2, have been developed to process the data obtained from a SHM system $[5,26]$. The methods mainly include Kalman filter (KF), fast 


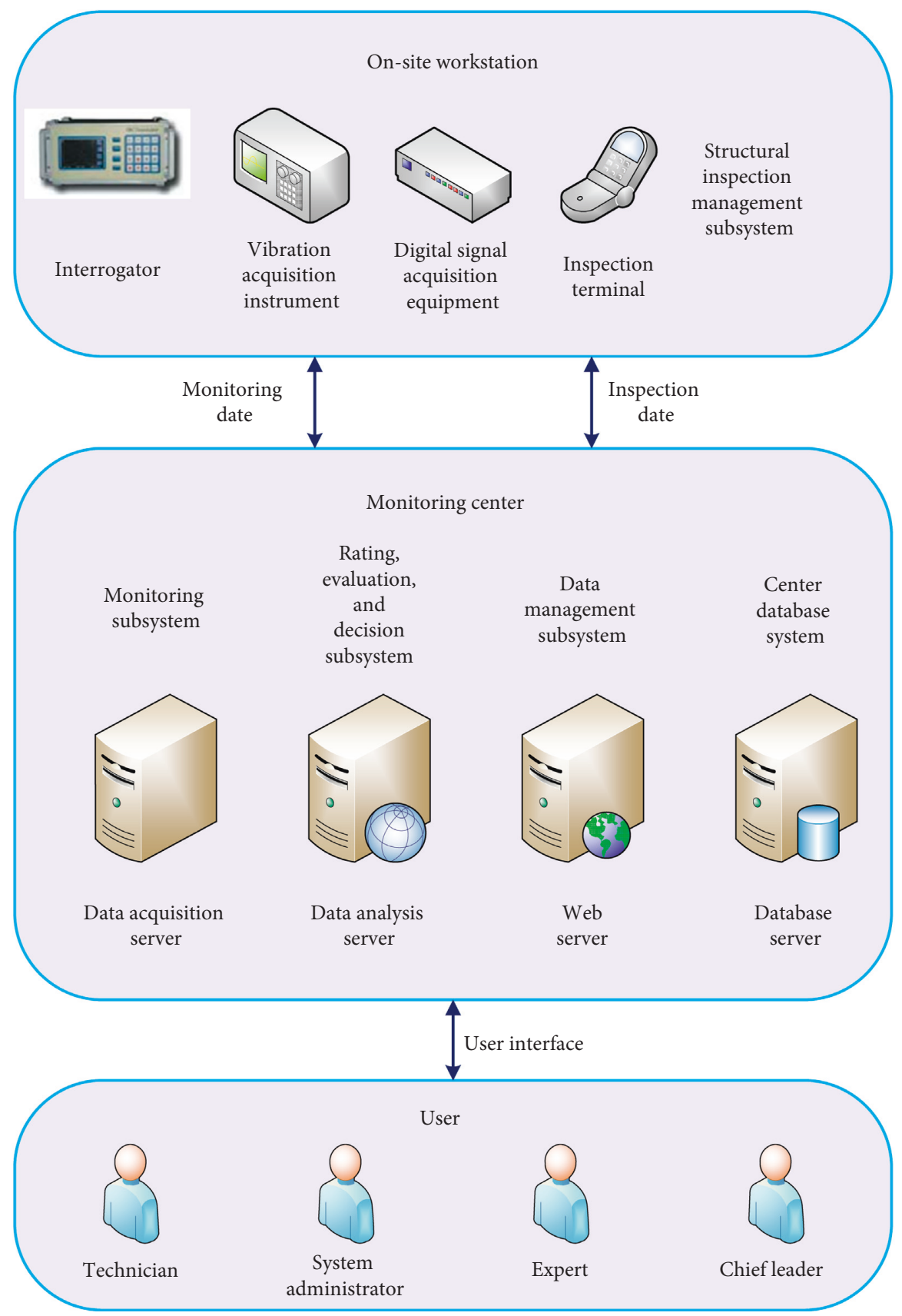

Figure 6: Physical deployment diagram of the system.

Fourier transform (FFT), short-time FFT (SFFT), wavelet transform (WT), S transform (ST), fast ST (FST), Hilbert transform (HT), Hilbert-Huang transform (HHT), multiple signal classification (MUSIC), and blind source separation (BSS). Then the dynamical characteristics of a structure, i.e., frequency and damping ratio, can be obtained by using the above methods.

Taking the method of HHT, for example, its identification steps to obtain the dynamical characteristics of a structure are as follows:

(1) First, the measured signal (such as acceleration response) is decomposed into a finite number of intrinsic mode functions (IMFs) through the Hilbert-Huang transform (HHT) [27]. Then, the corresponding frequency of each IMF is obtained by power spectrum density analysis. Figure 8 demonstrates the components of intrinsic mode decomposition for an acceleration signal by using the HHT method [28].

(2) Random decrement technique (RDT) [29] is used for each mode to identify the corresponding damping ratio. Actually, the key point for RDT is an averaging process which is also called a random decrement process. For a time series $x\left(t_{n}\right)$, the signal can be extracted by using the RDT method that averages time series $x\left(t_{n}\right)$, and then random decrement signature $D_{X X}(\tau)$ is 
TABLE 1: Monitoring contents and corresponding sensors.

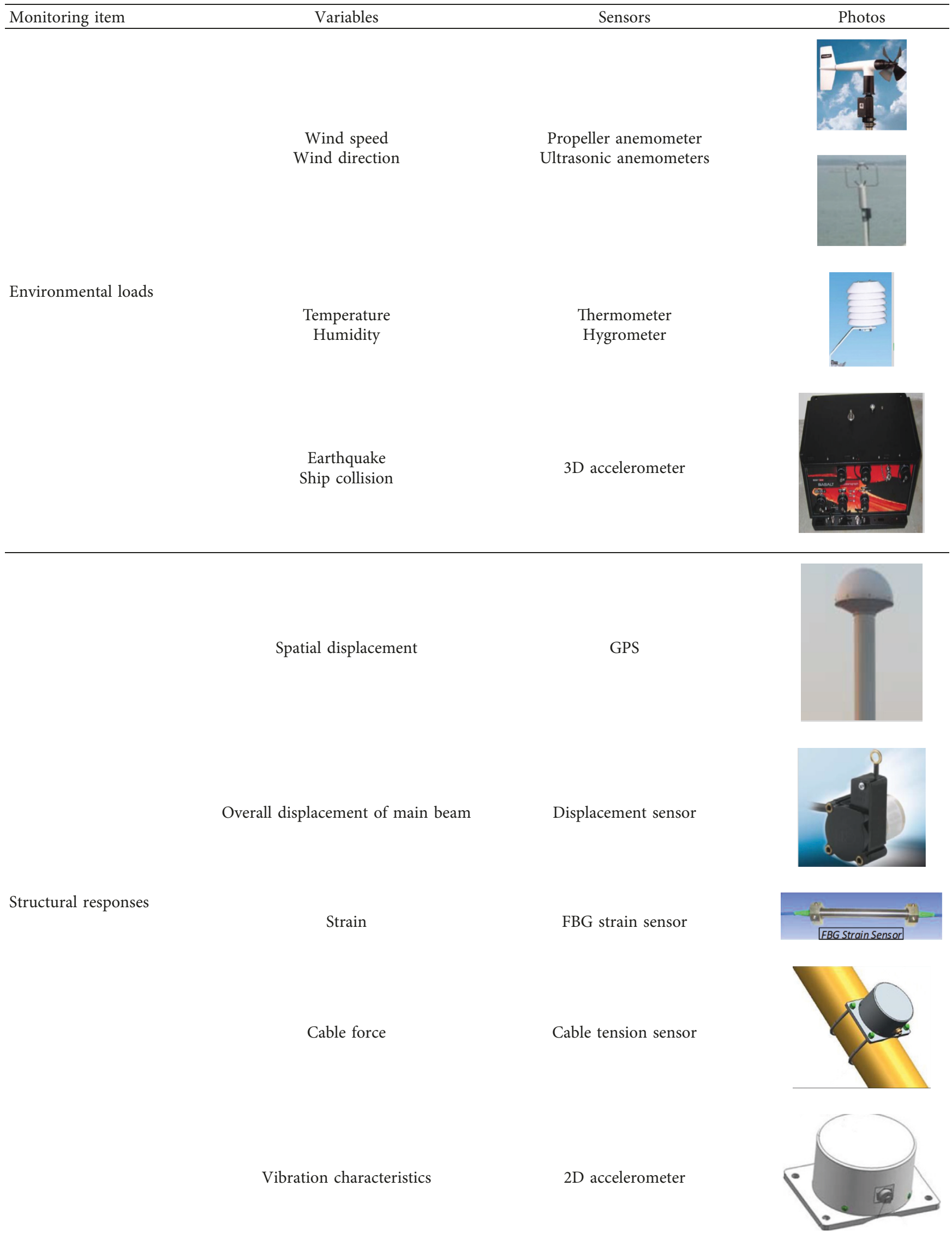


TABle 1: Continued.

\begin{tabular}{lccc}
\hline Monitoring item & Variables & Sensors & Photos \\
\hline Corrosion & Corrosion process & Corrosion sensor
\end{tabular}

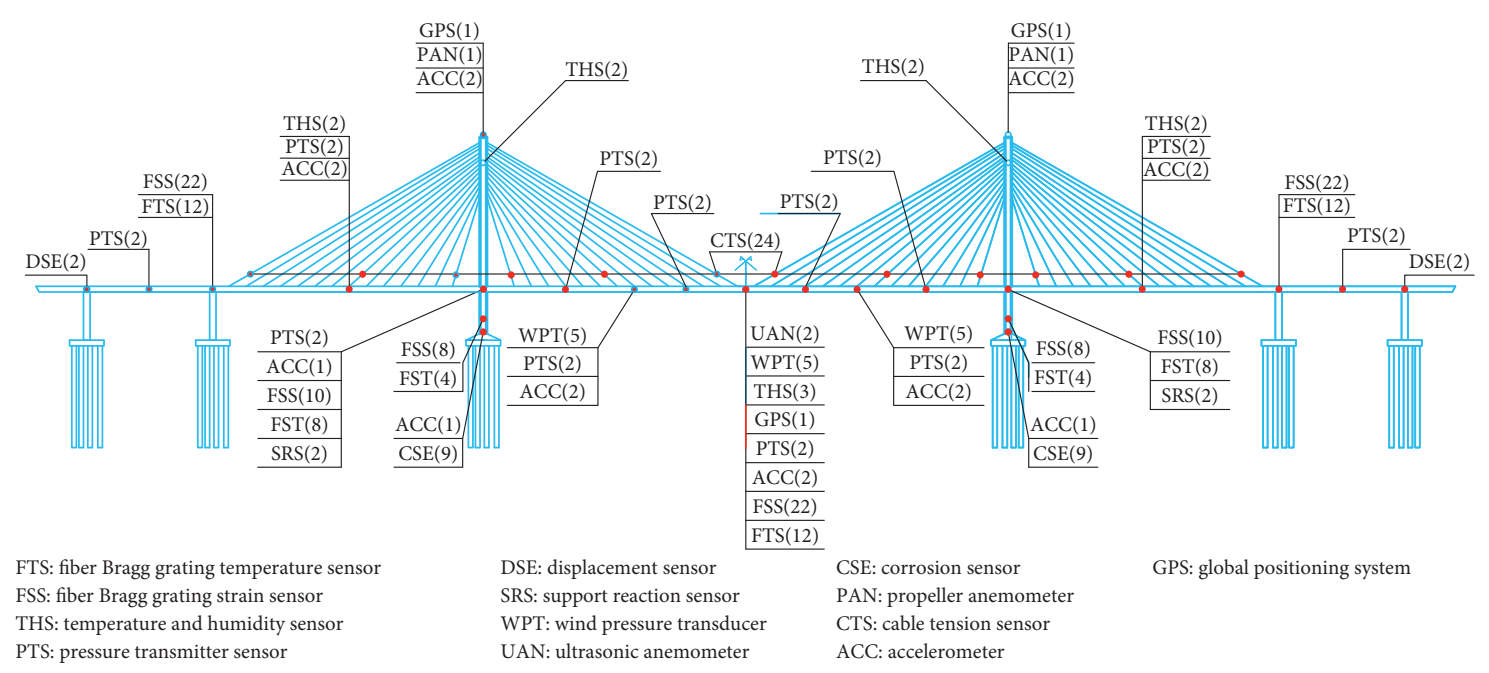

Figure 7: General layout of the sensors on the Qingzhou Shipping Channel Bridge.

TABle 2: Data analysis methods $[5,26]$.

\begin{tabular}{|c|c|c|}
\hline Methods & Advantages & Disadvantages \\
\hline KF & $\begin{array}{l}\text { Good signal-noise ratio; } \\
\text { good estimation of change in time }\end{array}$ & $\begin{array}{c}\text { Time consuming; } \\
\text { requires parameter calibration; } \\
\text { limited convergence speed and tracking accuracy }\end{array}$ \\
\hline FFT & $\begin{array}{l}\text { Nonlinear model; } \\
\text { model linear and nonlinear system; } \\
\text { ease of implementation; } \\
\text { simplicity }\end{array}$ & $\begin{array}{c}\text { Not applicable for complex system; } \\
\text { requires calibration to find model order; } \\
\text { sensitive to noise; } \\
\text { only frequency-domain representation }\end{array}$ \\
\hline MUSIC & $\begin{array}{l}\text { High resolution in frequency domain; } \\
\text { closely spaced modes can be estimated }\end{array}$ & Time consuming \\
\hline SFFT & $\begin{array}{l}\text { Ease of implementation; } \\
\text { time-frequency-domain representation; } \\
\text { simplicity }\end{array}$ & $\begin{array}{l}\text { Requires large quantity of samples; } \\
\text { limited time-frequency resolution; } \\
\text { not applicable for nonlinear and transient signals }\end{array}$ \\
\hline WT & $\begin{array}{l}\text { Good time-frequency resolution; } \\
\text { good signal-noise ratio; } \\
\text { a mother wavelet can be used for different application }\end{array}$ & $\begin{array}{l}\text { Spectral leakage; } \\
\text { requires several levels of decomposition; } \\
\text { mother wavelet will affect the results; } \\
\text { "end effect" is significant }\end{array}$ \\
\hline ST & $\begin{array}{c}\text { Good time-frequency resolution; } \\
\text { high signal-noise ratio; } \\
\text { adaptive method; } \\
\text { ease of implementation } \\
\text { Time saving; }\end{array}$ & $\begin{array}{l}\text { Time consuming; } \\
\text { requires calibration }\end{array}$ \\
\hline FST & $\begin{array}{l}\text { good time-frequency resolution; } \\
\text { spectrum can be localized in time domain }\end{array}$ & The application in SHM systems need exploring \\
\hline
\end{tabular}


TABle 2: Continued.

\begin{tabular}{|c|c|c|}
\hline Methods & Advantages & Disadvantages \\
\hline HHT & $\begin{array}{l}\text { Good time-frequency resolution; } \\
\text { high signal-noise ratio; } \\
\text { adaptive method; } \\
\text { ease of implementation }\end{array}$ & $\begin{array}{l}\text { Mode mixing; } \\
\text { requires calibration }\end{array}$ \\
\hline BSS & $\begin{array}{l}\text { Good signal-noise ratio; } \\
\text { closely spaced modes can be estimated; } \\
\text { good accuracy to separate frequency components }\end{array}$ & $\begin{array}{c}\text { Requires calibration; } \\
\text { nonlinear and transient signals cannot be analyzed } \\
\text { adequately }\end{array}$ \\
\hline
\end{tabular}

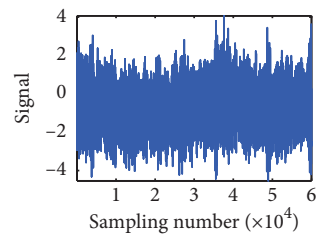

(a)

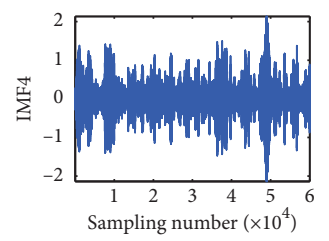

(e)

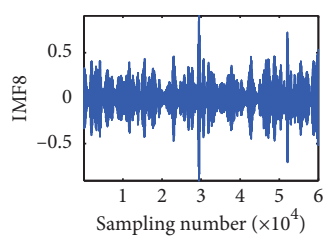

(i)

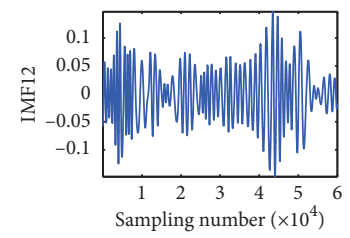

(m)

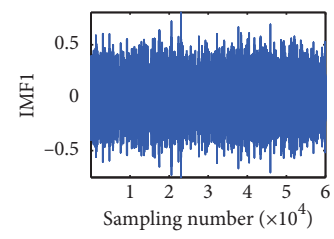

(b)

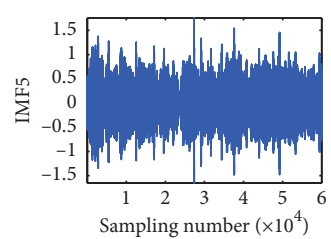

(f)

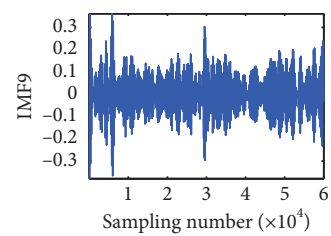

(j)

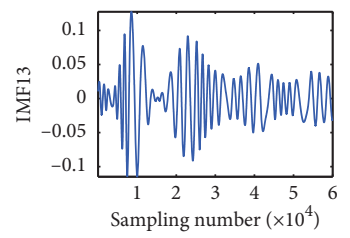

(n)

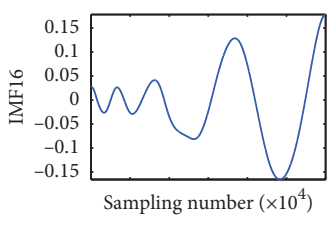

(q)

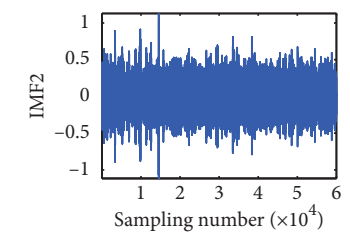

(c)

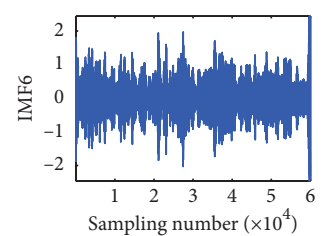

(g)

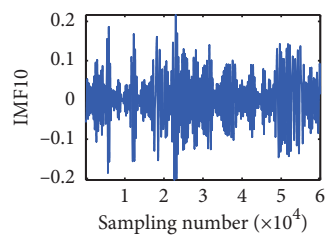

(k)

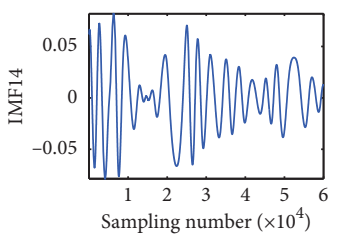

(o)

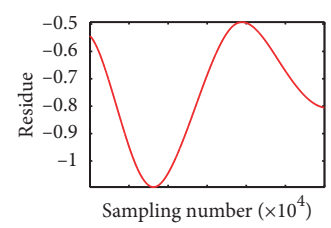

(r)

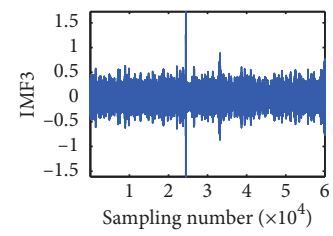

(d)

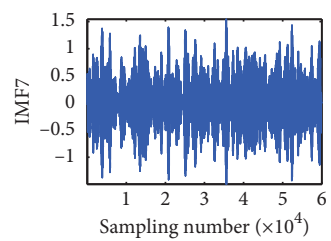

(h)

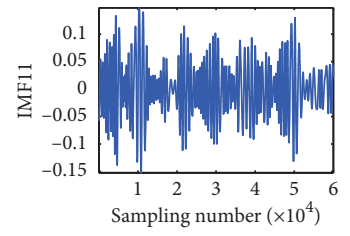

(l)

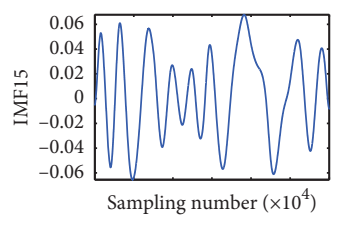

(p)

FIGURE 8: Components of intrinsic mode decomposition of an acceleration signal [28]: (a) acceleration signal, (b) IMF 1, (c) IMF 2, (d) IMF 3, (e) IMF 4, (f) IMF 5, (g) IMF 6, (h) IMF 7, (i) IMF 8, (j) IMF 9, (k) IMF 10, (l) IMF 11, (m) IMF 12, (n) IMF 13, (o) IMF 14, (p) IMF 15, (q) IMF 16, and (r) residue.

$$
D_{X X}(\tau)=\frac{1}{N} \sum_{n=1}^{N} x\left(t_{n}+\tau\right) x\left(t_{n}\right)=a,
$$

where $a$ is a trigger level [5]. The identified first-order modal damping ratio corresponding to IMF1 shown in Figure 8 is presented in Figure 9 [28]. 


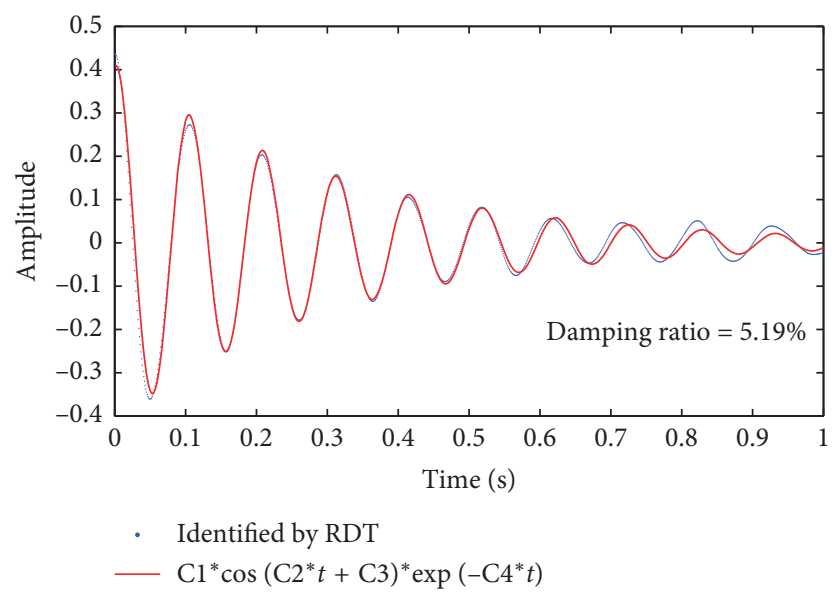

FIgURE 9: Identified process to obtain the first-order modal damping ratio [28].

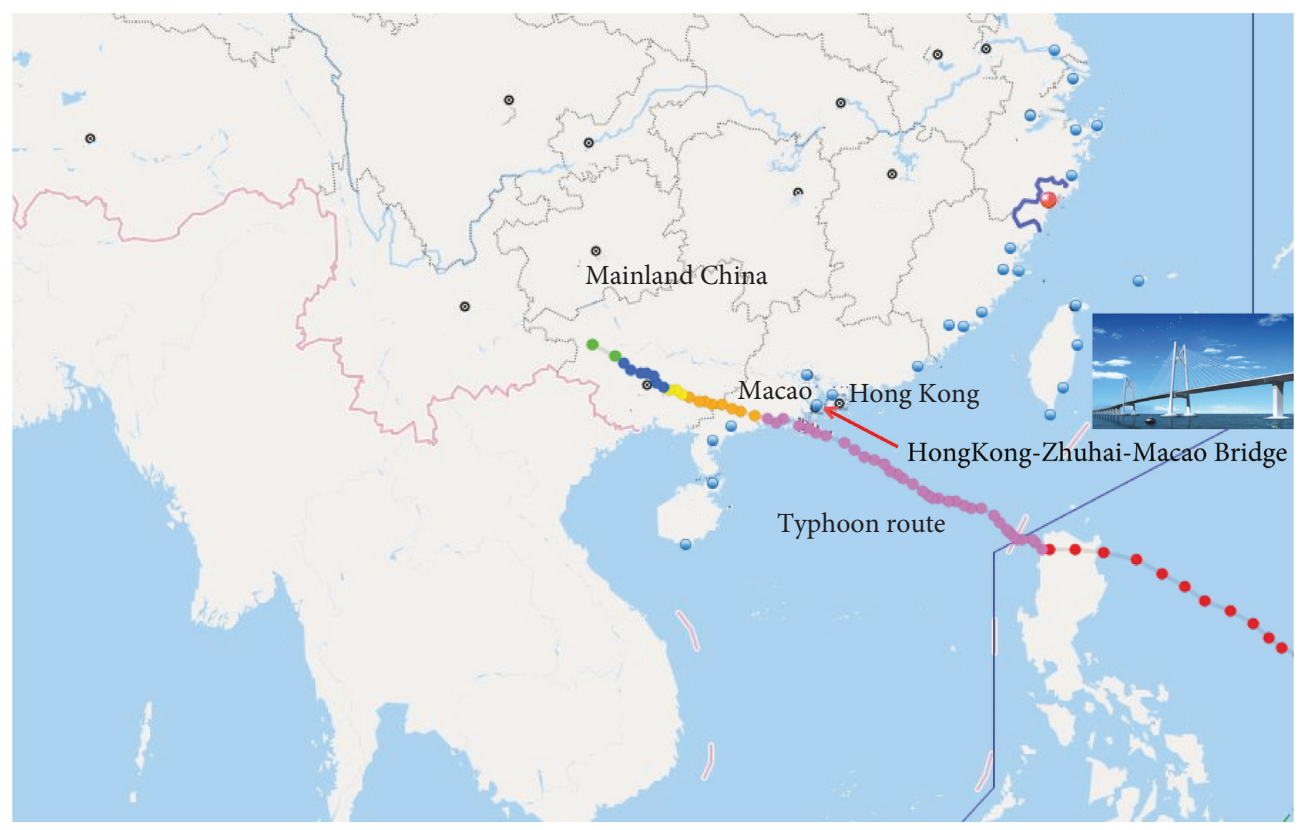

Figure 10: Typhoon Mangkhut's route.

\section{Implementation of the Bridge Health Monitoring System}

The Hong Kong-Zhuhai-Macao Bridge Health Monitoring System with an integrated bridge, island, and tunnel is the first full-coverage monitoring system for the superlarge seacrossing project. It has much monitoring contents, numerous monitoring taps, complex network architecture, and difficult platform design. High-quality original monitoring data are required to enable the system to serve the operation, maintenance, and management of the bridge at a high level. In the aspect of system integration, various measures, such as construction industrialization based on a small system experiment, data multilayer storage system based on SAN (optical fiber local area network), a fault-tolerant data center platform design, and an open comprehensive supervision platform design, are used. These measures ensure the reliability and advancement of the system.

\section{Typhoon Mangkhut and Monitoring Results}

5.1. Typhoon Mangkhut and Its Wind Characteristics. Typhoon Mangkhut was the No. 22 supertyphoon in 2018, and its path is shown in Figure 10. Typhoon Mangkhut was formed on the Northwest Pacific Ocean at 20:00 on September 7, 2018. Typhoon Mangkhut landed the northern part of the Philippines on September 15. Then, it landed in Haiyan Town, Taishan City, Guangdong Province, China, at 17:00 on September 16 . The maximum wind force level near the center was 14 , and the minimum pressure of the center was 95,500 $\mathrm{Pa}$.

Figure 11 shows the $10 \mathrm{~min}$ averaged wind speed and wind direction recorded by using the ultrasonic anemometer located at the Jiuzhou Shipping Channel Bridge from 0:00 to 18:00 on September 16. The mean speed gradually increases and achieves its maximum value of $34.6 \mathrm{~m} / \mathrm{s}$ at 14:30, and the corresponding horizontal and vertical wind directions are $257.3^{\circ}$ and $7.5^{\circ}$, respectively. Subsequently, the mean speed 


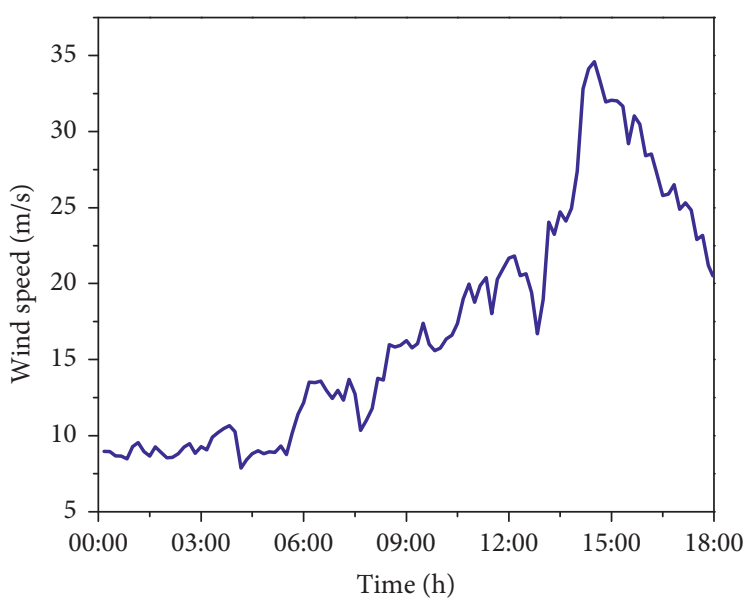

(a)

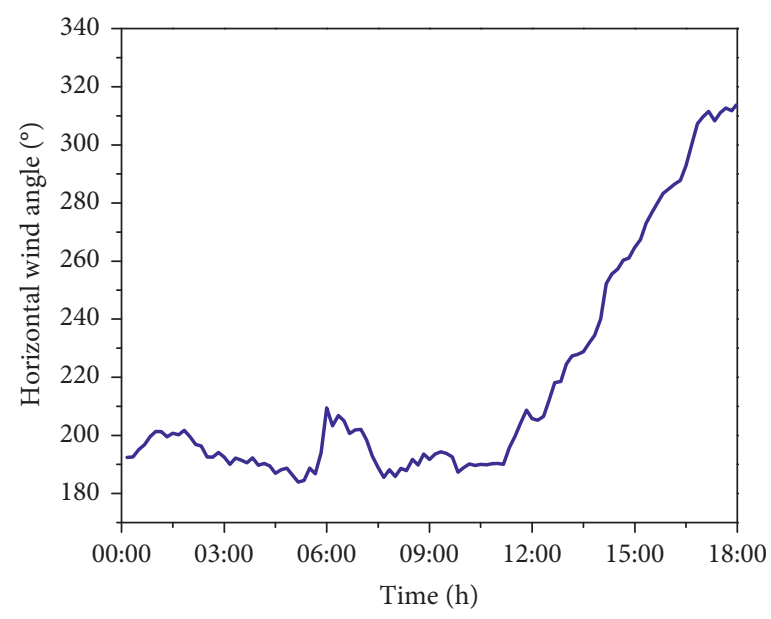

(b)

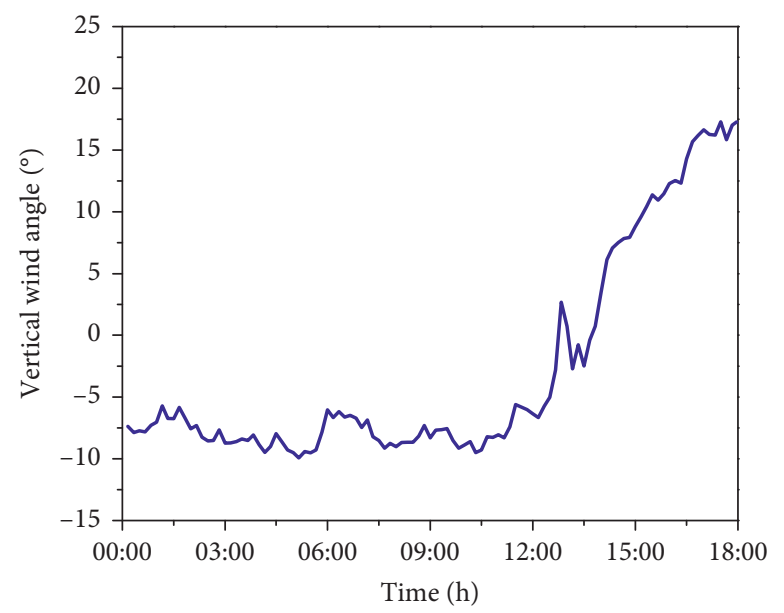

(c)

Figure 11: (a) Mean speed. (b) Horizontal wind direction. (c) Vertical wind direction.

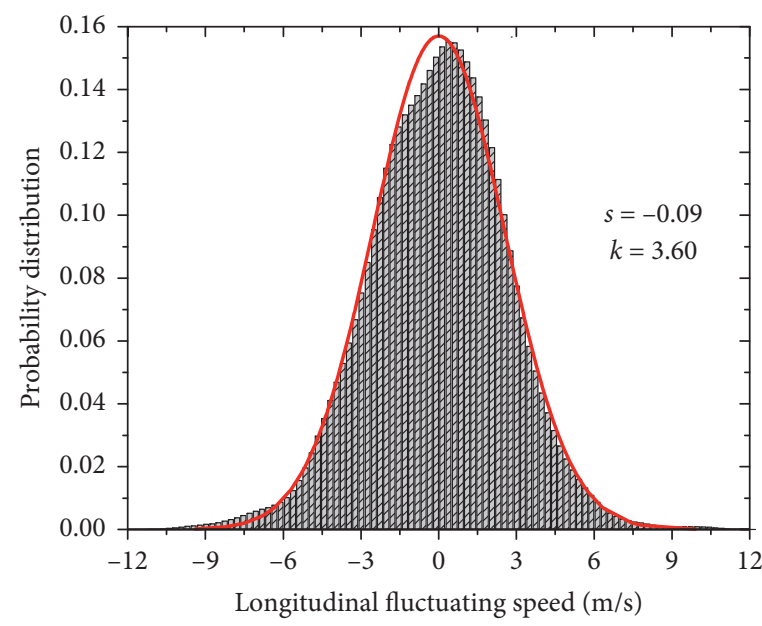

VIII Measured data - Gaussian distribution

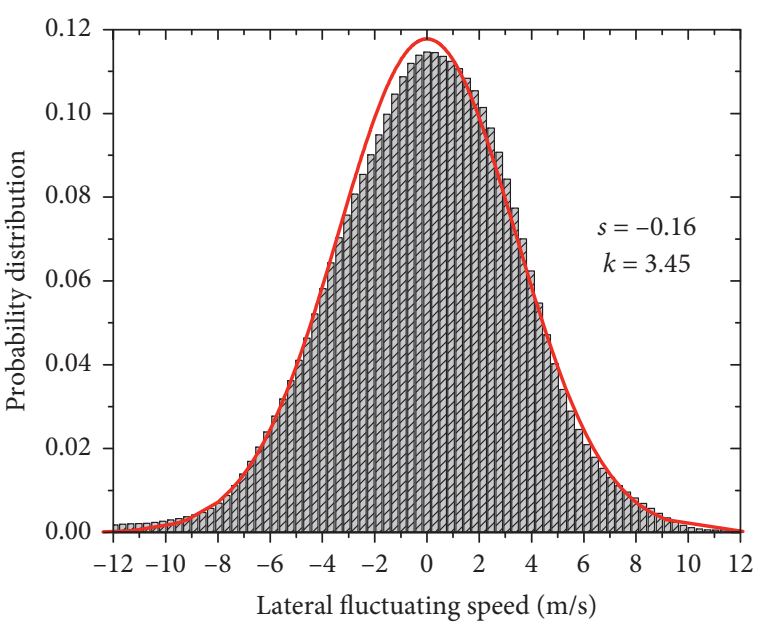

VIIIA Measured data - Gaussian distribution

(a)

(b)

Figure 12: Continued. 


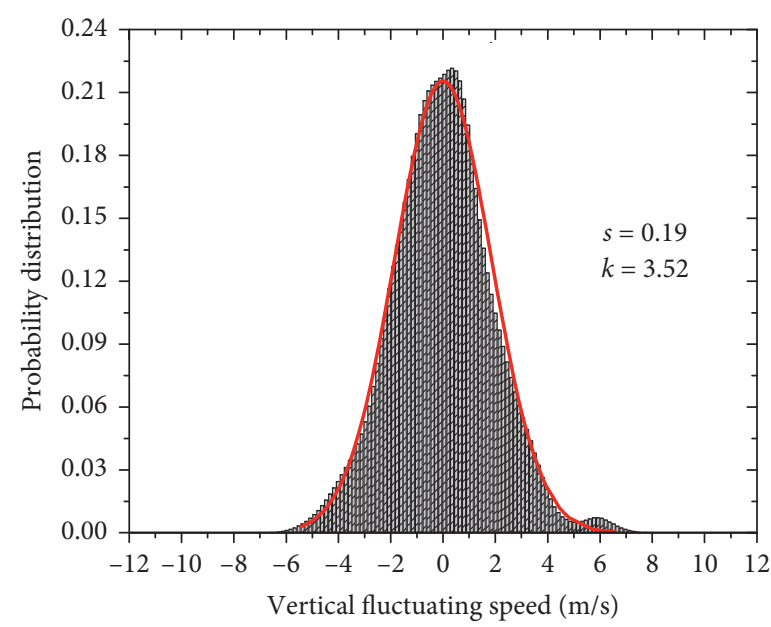

VIIIA Measured data

Gaussian distribution

(c)

FIGURE 12: Probability density distribution of wind speed. (a) Longitudinal direction. (b) Lateral direction. (c) Vertical direction.

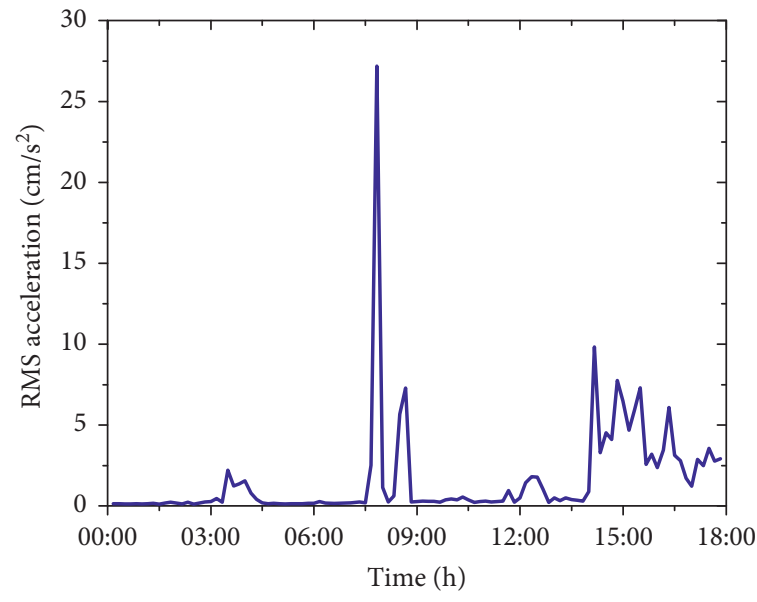

(a)

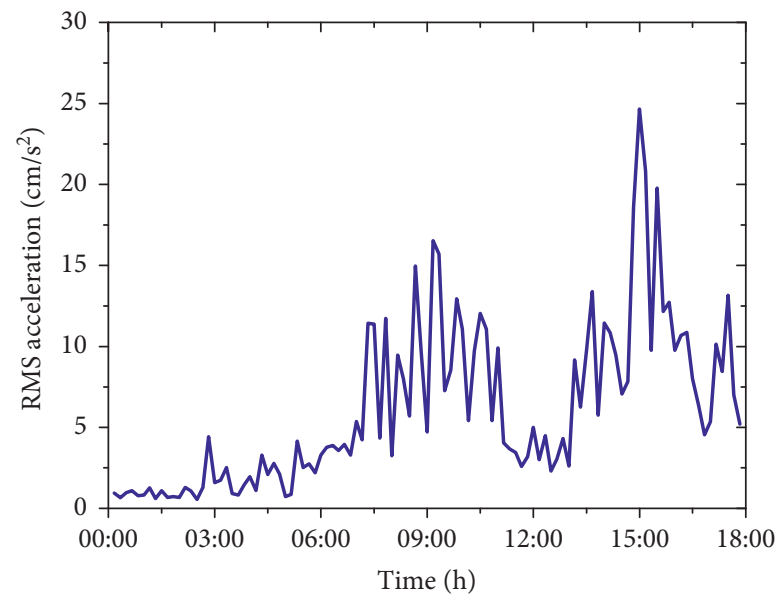

(b)

FIGURE 13: Time history of the 10 min averaged RMS acceleration response. (a) Vertical RMS acceleration and (b) lateral RMS acceleration at the middle position of the main span.

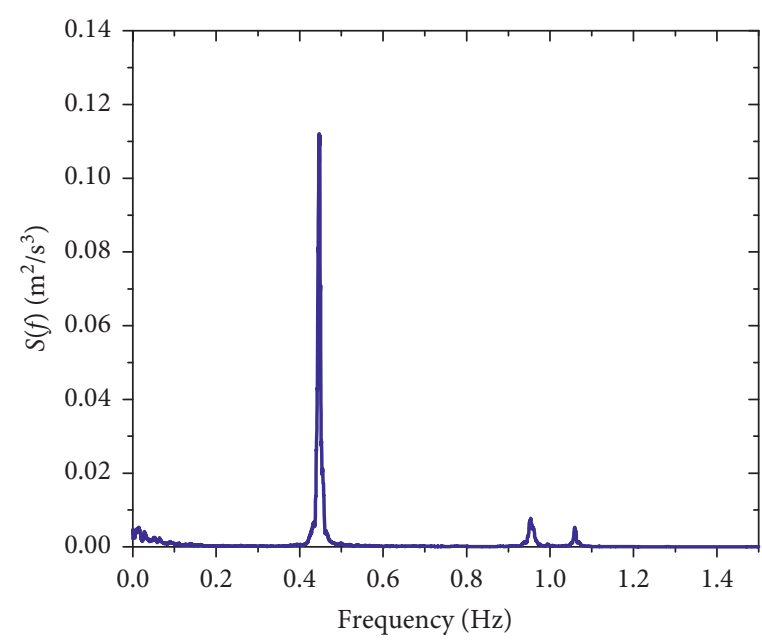

(a)

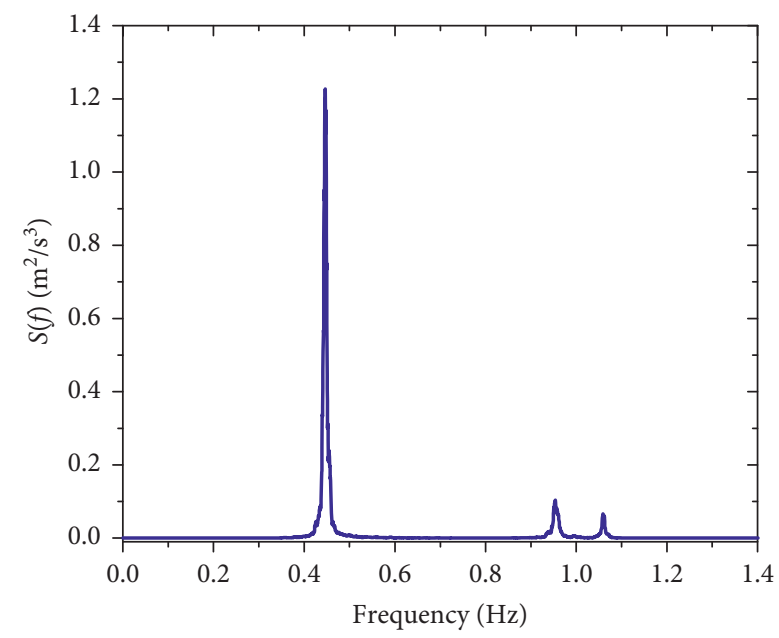

(b)

FIGURE 14: Power spectrum densities of acceleration responses. (a) Vertical direction. (b) Lateral direction. 
decreases, whereas the horizontal and vertical wind directions experience remarkable variation. The maximum horizontal and vertical directions are $327.4^{\circ}$ and $19.4^{\circ}$, respectively.

The time history of wind speed recorded from 14:30 to 14:40 is considered an example. The corresponding probability density distributions of the fluctuating speed in the longitudinal, lateral, and vertical directions are presented in Figure 12. The values of skewness $(s)$ and kurtosis $(k)$ are -0.09 and 3.60 for longitudinal speed, -0.16 and 3.45 for lateral speed, and 0.19 and 3.52 for vertical speed. Thus, the fluctuating speeds in the three directions nearly obey the Gaussian distribution $(s=0, k=3.0)$.

5.2. Measured Acceleration Responses. Figure 13 presents the time history of the $10 \mathrm{~min}$ averaged RMS acceleration response. RMS acceleration responses are recorded at the middle position of the main span of Jiuzhou Bridge from 0 : 00 to 18:00 on September 16. The maximum values of the RMS accelerations are 27.19 and $24.65 \mathrm{~cm} / \mathrm{s}^{2}$ in the vertical and lateral directions, respectively.

The corresponding power spectrum densities, which are obtained by analyzing the time history of acceleration responses recorded from 17:00 to 18:00, are shown in Figure 14. As expected, a resonance peak is evident in both plots. The observed resonance frequency is $0.45 \mathrm{~Hz}$, which corresponds to the natural frequency of the Jiuzhou Shipping Channel Bridge.

\section{Conclusions}

The Hong Kong-Zhuhai-Macao Bridge is a $55 \mathrm{~km}$ bridgetunnel system consisting of three cable-stayed bridges, an undersea tunnel, and four artificial islands. To ensure the operational safety of the Hong Kong-Zhuhai-Macao Bridge, an innovative structural health monitoring (SHM) system is established by combining automated health monitoring technology with manual inspection technology. Many contemporary technologies and equipment, such as modern sensor testing, signal analysis, remote intelligent control, computer technology, damage identification, and structural safety assessment, are used in the design and implementation of this SHM system.

Under supertyphoon Mangkhut in 2018, the monitoring results, including environment load (wind characteristics near the bridge deck and tower, structural temperature, and humidity) and structural dynamic responses (structural spatial deformations, stress, and support reaction), are recorded by this SHM system, and partial results are displayed. The proposed health monitoring system can accurately and reliably monitor and feedback the environmental loads and structural responses of the principal component of the Hong Kong-Zhuhai-Macao Bridge under complicated service environment. However, the extensive properties, their underlying mechanisms, and the long-term erosion process of this bridge require further research and will be investigated in future studies.

\section{Data Availability}

All data, models, and code generated or used during the study are included within the article.

\section{Conflicts of Interest}

The authors declare no conflicts of interest.

\section{Acknowledgments}

This work was supported by the Characteristic Innovation Project of Universities in Guangdong Province (Grant no. 2018KTSCX004), the Key Project of Foundation and Frontier Research of Chongqing (Grant no. cstc2017jcyjAX0187), and the National Natural Science Foundation of China (Grant no. 51708074).

\section{References}

[1] K. Wardhana and F. C. Hadipriono, "Analysis of recent bridge failures in the United States," Journal of Performance of Constructed Facilities, vol. 17, no. 3, pp. 144-150, 2003.

[2] R. C. Sharma, R. Tateishi, K. Hara, H. T. Nguyen, S. Gharechelou, and L. V. Nguyen, "Earthquake damage visualization (EDV) technique for the rapid detection of earthquake -induced damages using SAR data," Sensors, vol. 17, no. 2, p. 235, 2017.

[3] Z. Alphose, "Structural health monitoring, damage detection and long term performance," Engineering Structures, vol. 27, no. 12, pp. 1713-1714, 2005.

[4] PIANC, Seismic Design Guidelines for Port Structures, AA Balkema Publishers, Leiden, The Netherlands, 2001.

[5] Z. Chen, X. Zhou, X. Wang, L. Dong, and Y. Qian, "Deployment of a smart structural health monitoring system for long-span arch bridges: a review and a case study," Sensors, vol. 17, no. 9, p. 2151, 2017.

[6] T.-H. Yi, H.-N. Li, and M. Gu, "Recent research and applications of GPS-based monitoring technology for high-rise structures," Structural Control and Health Monitoring, vol. 20, no. 5, pp. 649-670, 2013.

[7] H. Wang, A. Q. Li, and R. M. Hu, "Comparison of ambient vibration response of the Runyang suspension bridge under skew winds with time-domain numerical predictions," Journal of Bridge Engineering, vol. 16, no. 4, pp. 513-526, 2011.

[8] T.-H. Yi, H.-N. Li, and M. Gu, "Experimental assessment of high-rate GPS receivers for deformation monitoring of bridge," Measurement, vol. 46, no. 1, pp. 420-432, 2013.

[9] H. Wang, A. Li, R. Hu, and J. Li, "Accurate stress analysis on steel box girder of long span suspension bridges based on multi-scale submodeling method," Advances in Structural Engineering, vol. 13, no. 4, pp. 727-740, 2010.

[10] T.-H. Yi, H.-N. Li, and X.-D. Zhang, "Sensor placement on Canton Tower for health monitoring using asynchronousclimb monkey algorithm," Smart Materials and Structures, vol. 21, no. 12, Article ID 125023, 2012.

[11] H. Wang, A. Li, C. Jiao, and B. F. Spencer, "Damper placement for seismic control of super-long-span suspension bridges based on the first-order optimization method," Science China Technological Sciences, vol. 53, no. 7, pp. 2008-2014, 2010.

[12] H. Wang, A. Li, G. Zhao, and J. Li, "Non-linear buffeting response analysis of long-span suspension bridges with 
central buckle," Earthquake Engineering and Engineering Vibration, vol. 9, no. 2, pp. 259-270, 2010.

[13] T. H. Yi, H. N. Li, and M. Gu, "Characterization and extraction of global positioning system multipath signals using improved particle filtering algorithm," Measurement Science and Technology, vol. 22, no. 7, Article ID 075101, 2011.

[14] J. Li, H. Hao, K. Fan, and J. Brownjohn, "Development and application of a relative displacement sensor for structural health monitoring of composite bridges," Structural Control and Health Monitoring, vol. 22, no. 4, pp. 726-742, 2015.

[15] G. D. Zhou, T. H. Yi, and B. Chen, "Innovative design of a health monitoring system and its implementation in a complicated long-span arch bridge," Journal of Aerospace Engineering, vol. 30, no. 2, Article ID B4016006, 2017.

[16] H. Wang, A. Li, J. Niu, Z. Zong, and J. Li, "Long-term monitoring of wind characteristics at Sutong bridge site," Journal of Wind Engineering and Industrial Aerodynamics, vol. 115, pp. 39-47, 2013.

[17] Y. Zhou and L. Sun, "Effects of high winds on a long-span seacrossing bridge based on structural health monitoring," Journal of Wind Engineering and Industrial Aerodynamics, vol. 174, pp. 260-268, 2018.

[18] Y. L. Xu, L. D. Zhu, K. Y. Wong, and K. W. Y. Chan, "Field measurement results of Tsing Ma suspension bridge during typhoon victor," Structural Engineering and Mechanics, vol. 10, no. 6, pp. 545-559, 2000.

[19] H. Wang, A. Q. Li, C. K. Jiao, and X. P. Li, "Characteristics of strong winds at the Runyang suspension bridge based on field tests from 2005 to 2008," Journal of Zhejiang UniversityScience A, vol. 11, no. 7, pp. 466-476, 2010.

[20] K. Y. Koo, J. M. W. Brownjohn, D. I. List, and R. Cole, "Structural health monitoring of the Tamar suspension bridge," Structural Control and Health Monitoring, vol. 20, no. 4, pp. 609-625, 2013.

[21] W. Liu, X. Wu, L. Zhang, Y. Wang, and J. Teng, "Sensitivity analysis of structural health risk in operational tunnels," Automation in Construction, vol. 94, pp. 135-153, 2018.

[22] J. P. Yang, W. Z. Chen, M. Li, X.-J. Tan, and J.-X. Yu, "Structural health monitoring and analysis of an underwater TBM tunnel," Tunnelling and Underground Space Technology, vol. 82, pp. 235-247, 2018.

[23] P. K. Dey, "Analytic hierarchy process analyzes risk of operating cross-country petroleum pipelines in India," Natural Hazards Review, vol. 4, no. 4, pp. 213-221, 2003.

[24] L. M. Schmitt, "Theory of genetic algorithms," Theoretical Computer Science, vol. 259, no. 1-2, pp. 1-61, 2001.

[25] F. Ian and K. Nabil, "Neural networks in civil engineering. I: principles and understanding," Journal of Computing in Civil Engineering, vol. 8, no. 2, pp. 131-148, 1994.

[26] J. P. Amezquita-Sanchez and H. Adeli, "Signal processing techniques for vibration-based health monitoring of smart structures," Archives of Computational Methods in Engineering, vol. 23, no. 1, pp. 1-15, 2016.

[27] N. E. Huang, Z. Shen, S. R. Long et al., "The empirical mode decomposition and the Hilbert spectrum for nonlinear and non-stationary time series analysis," Proceedings of the Royal Society, London, vol. 454, no. 1971, pp. 903-995, 1998.

[28] X. Yu, Z. Xie, and M. Gu, "Coupling vibration between windinduced internal pressure and a flexible roof for buildings with a dominant opening and background leakage," KSCE Journal of Civil Engineering, vol. 23, no. 9, pp. 4075-4084, 2019.

[29] S. R. Ibrahim, "Random decrement technique for modal identification of structures," Journal of Spacecraft and Rockets, vol. 14, no. 11, pp. 696-700, 1977. 


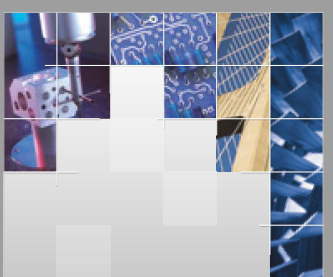

\section{Enfincering}
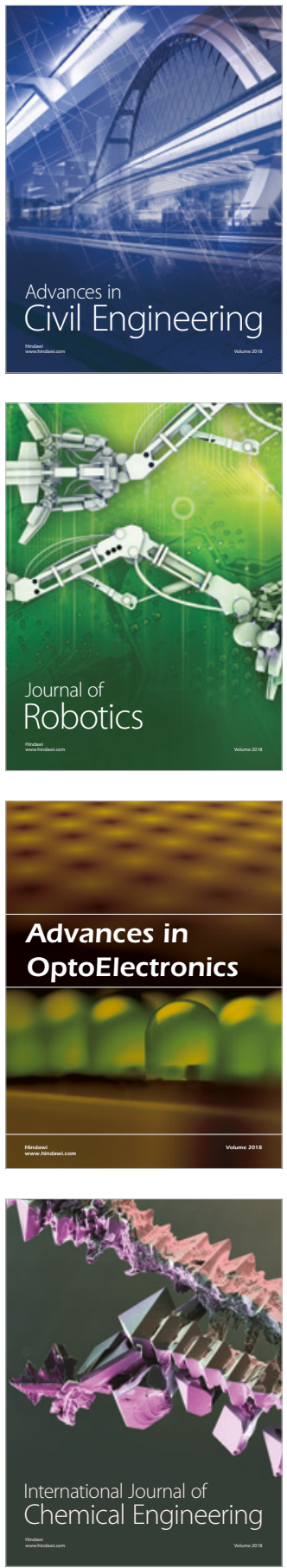

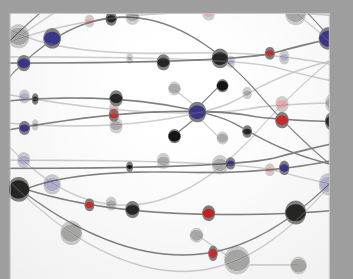

\section{Rotating \\ Machinery}

The Scientific World Journal

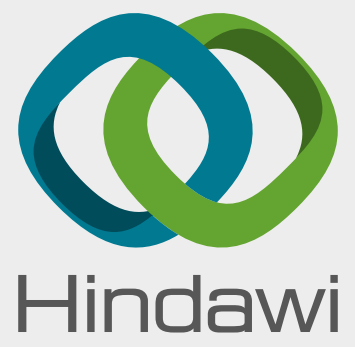

Submit your manuscripts at

www.hindawi.com
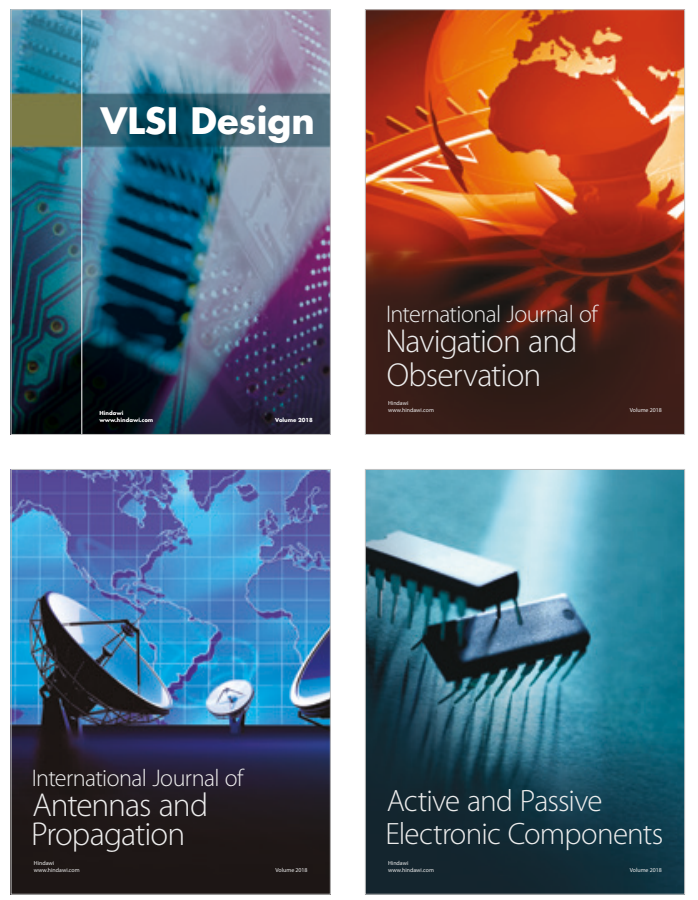
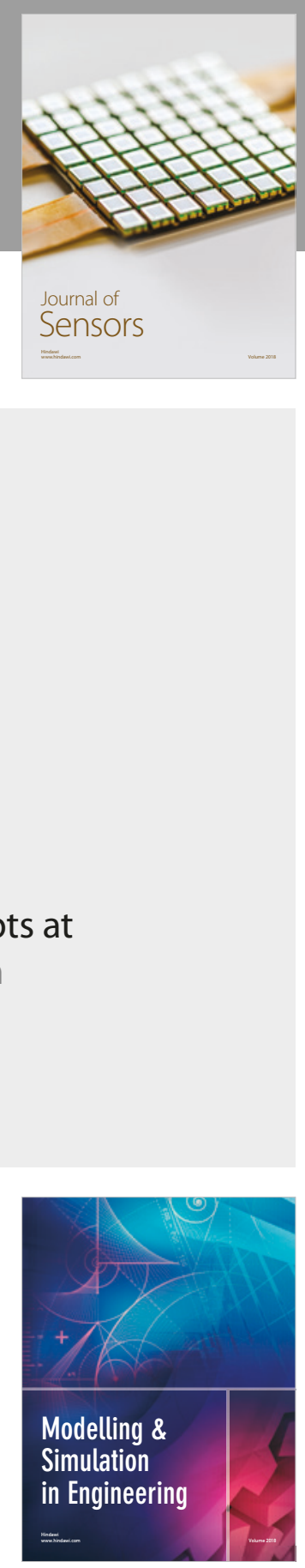

\section{Advances \\ Multimedia}
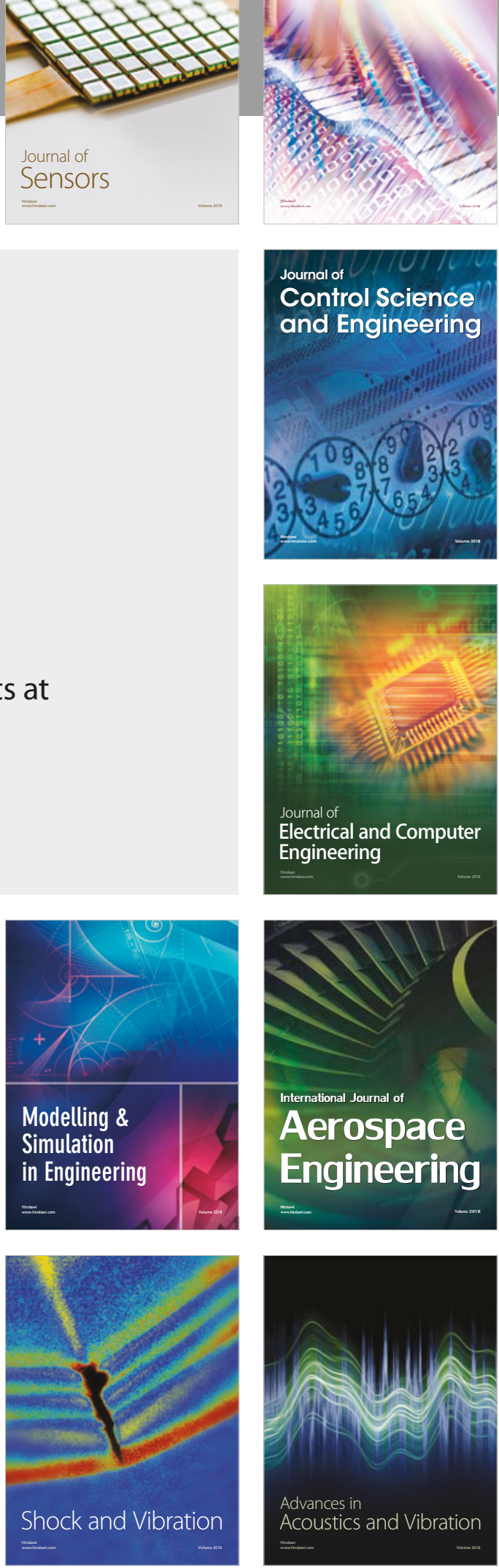